\title{
Preparation of a Periodically Ordered Mesoporous Organosilica Material Using Chiral Building Blocks**
}

\author{
By Sebastian Polarz* and Andreas Kuschel
}

Ordered mesoporous materials (OMMs), of which MCM41 is perhaps the most prominent example, ${ }^{[1]}$ are characterized by well-defined pore systems and large surface areas on the order of $700-1000 \mathrm{~m}^{2} \mathrm{~g}^{-1}$. This makes OMMs very interesting for numerous applications, such as in chromatographic separation or as supports for catalytically active compounds. ${ }^{[2]}$ Conventional pure silica materials are somewhat limited in their range of functional properties. Therefore, the preparation of high-surface-area (porous) organic-inorganic hybrid materials has received a lot of attention. ${ }^{[3]}$ The modification of mesoporous silica materials with organic groups can be achieved in three different ways. Because of the reactive $\mathrm{Si}-$ $\mathrm{OH}$ groups on the pore walls of OMMs, it is possible to use silane derivatives $\mathrm{X}_{3-y} \mathrm{Si}-\mathrm{R}_{y}\left(\mathrm{X}=\mathrm{OR}^{\prime}\right.$ or halogen; $\mathrm{R}$ is an organic group) to carry out a post-synthetic grafting process. ${ }^{[4]}$ Alternatively, the silane derivatives can be used directly during the synthesis of the OMMs. ${ }^{[5]}$ However, a major drawback of these two techniques is that, depending on the steric requirements and the degree of hydrophobicity of the silanes, only a fraction of the inorganic matrix can be organically modified. Typically, not more than $25 \%\left(\mathrm{R}^{\prime} \mathrm{O}\right)_{3} \mathrm{Si}-\mathrm{R}$ can be used in a co-condensation process. The rest of the material network is formed with $\mathrm{Si}\left(\mathrm{OR}^{\prime}\right)_{4}$ as the source, yielding purely inorganic $\mathrm{SiO}_{2}$.

The recent development of the so-called periodically ordered mesoporous organosilica materials (PMOs) seems to be a solution to the above-mentioned problems. ${ }^{[6]}$ Bis-alkoxysilanes with a bridging organic group $\left(\mathrm{R}^{\prime} \mathrm{O}\right)_{3} \mathrm{Si}-\mathrm{R}-\mathrm{Si}\left(\mathrm{OR}^{\prime}\right)_{3}$ are used as precursors for the formation of mesoporous $\mathrm{RSi}_{2} \mathrm{O}_{3}$ materials. The "interface contact" of the bridging organic groups is maximized for PMO materials that contain "undiluted" $\mathrm{O}_{1.5} \mathrm{Si}-\mathrm{R}-\mathrm{SiO}_{1.5}$ motifs. ${ }^{[7]}$ The advantage of using the bis-alkoxysilanes is that the addition of $\mathrm{Si}\left(\mathrm{OR}^{\prime}\right)_{4}$ and its cocondensation is not mandatory for obtaining highly ordered materials. A further advantage of this interesting and new class of materials is their enhanced mechanical stability; ${ }^{[8]}$ also, the use of molecular building blocks leads to the homo-

[*] Dr. S. Polarz, A. Kuschel Technical University Berlin, Institute of Chemistry Strasse des 17. Juni 135, 10623 Berlin (Germany) E-mail: sebastian.polarz@tu-berlin.de

[**] The work has been funded by the German Science Foundation (DFG) in the framework of an Emmy-Noether research grant. Prof. M. Driess is gratefully acknowledged for his generous support. We thank Dr. A. Thomas, Prof. M. Antonietti, and Prof. G. A. Ozin for helpful discussions. geneous distribution and accessibility of the organic groups. ${ }^{[6,9]}$ PMOs can contain more than one group bound to each $\mathrm{Si}$ atom, ${ }^{[10]}$ and the assembly of larger PMO building blocks like dendrimers has also been reported. ${ }^{[11]}$ Although the number of bis-alkoxysilanes used as precursors for PMOs is steadily increasing, ${ }^{[12]}$ the field is still quite unexplored. Therefore, a PMO material containing $\mathrm{O}_{1.5} \mathrm{Si}-\mathrm{R}-\mathrm{SiO}_{1.5}$, where $\mathrm{R}$ possesses a chiral group, represents a very tempting target.

To the best of our knowledge, there has been only one previous report of a comparable system. ${ }^{[13]}$ The previous work described the synthesis of a mesoporous material by the cocondensation route involving a bis-alkoxysilane with a chiral vanadyl salen complex as the bridging organic ligand along with tetraethoxysilane (TEOS) ${ }^{[13]}$ The maximum amount of the chiral bis-alkoxysilane used was $15 \%$, and the new sol-gel precursor contains a potentially labile thioether group. A cocondensation process was probably necessary in order to incorporate the large and hydrophobic salen complex into the mesoporous framework. In order to overcome the increased hydrophobicity, the authors used ethanol as a co-solvent. ${ }^{[13]}$

The key to obtaining a PMO material from a single precursor is therefore the synthesis of a bis-alkoxysilane with a chiral bridging organic group that is as small as possible, while also being potentially hydrophilic. Fairly well-ordered PMO materials have been prepared using $\left(\mathrm{R}^{\prime} \mathrm{O}\right)_{3} \mathrm{Si}-\mathrm{CH}_{2} \mathrm{CH}_{2}-\mathrm{Si}\left(\mathrm{OR}^{\prime}\right)_{3}$ as a precursor. ${ }^{[14]}$ Thus, molecules $\left(\mathrm{R}^{\prime} \mathrm{O}\right)_{3} \mathrm{Si}-\mathrm{CHXCH}_{2}-$ $\mathrm{Si}\left(\mathrm{OR}^{\prime}\right)_{3}$ represent an attractive group of chiral PMO precursors, where $\mathrm{X}$ can be any group except hydrogen. In this paper, we report the synthesis of a PMO precursor of this type and use it to prepare an ordered mesoporous material. Co-condensation with an additional tetraalkoxysilane is not necessary in order to obtain a well-ordered material. We have used the synthetic approach shown in Scheme 1 to prepare the desired compound.

First, bis(1,2-trimethoxysilyl)ethene is prepared via a metathesis reaction, as previously reported in the literature. ${ }^{[15]}$ The enantioselective hydroboration of carbon-carbon double bonds is a well-established technique. ${ }^{[16]}$ We have adapted this method by using rhodium(I) catalysts in combination with $(R)-(+)-2,2^{\prime}$-bis(diphenylphosphino)-1,1'-binaphthalene $(R$-BINAP) as a chiral ligand (see Experimental). The product $\mathbf{2}$ is obtained as a colorless liquid. The compound is purified under high vacuum $\left(p=10^{-5} \operatorname{mbar} ; 1 \mathrm{mbar}=100 \mathrm{~Pa}\right)$ at a temperature of $150{ }^{\circ} \mathrm{C}$ using bulb-to-bulb distillation. However, due the sensitive character of the compound, the final yield of the pure product is only $35 \%$. NMR investigations in- 


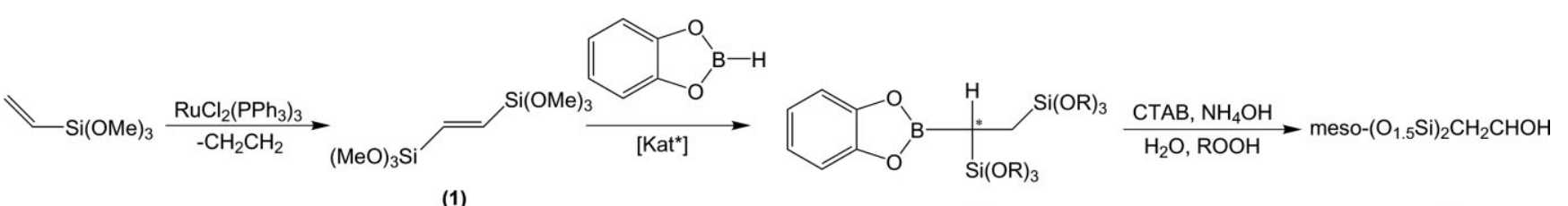

(1)

(2)

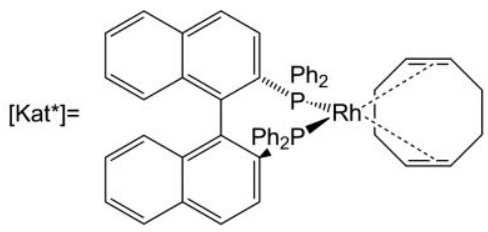

Scheme 1. Synthesis of porous material (3). CTAB: cetyltrimethylammonium bromide.

dicate that at higher temperatures a dehydrosilylation reaction takes place. The hydroboration reaction has been followed by ${ }^{1} \mathrm{H},{ }^{29} \mathrm{Si}$, and ${ }^{11} \mathrm{~B}$ NMR spectroscopy, as shown in Figure 1.

During the course of the reaction (Scheme 1), the ${ }^{1} \mathrm{H}$ NMR signal corresponding to the $\mathrm{C}=\mathrm{C}$ bond in $\mathbf{1}(\delta=6.71 \mathrm{ppm})$ gradually disappears, accompanied by the emergence of two new signals ( $\delta=0.98 \mathrm{ppm}, 2 \mathrm{H}$ and $\delta=1.44 \mathrm{ppm}, 1 \mathrm{H})$, which we attribute to the formation of the $\mathrm{CH}-\mathrm{CH}_{2}$ group. The two methoxy groups at the silicon now show slightly different chemical shifts $(\delta=3.63 \mathrm{ppm}, 9 \mathrm{H}$ and $\delta=3.54 \mathrm{ppm}, 9 \mathrm{H})$. Furthermore, the aromatic protons in the catechol group can also be seen in the spectrum of 2 (Fig. 1a). Similarly, the ${ }^{13} \mathrm{C}$ NMR signal characteristic of the $\mathrm{C}=\mathrm{C}$ bond $(\delta=145 \mathrm{ppm})$ disappears (spectrum not shown). In the ${ }^{11} \mathrm{~B}$ NMR spectrum, only one broad signal at $\delta=-1.4 \mathrm{ppm}$ is found, which is markedly different from the reducing agent catecholborane $(\delta=5.9 \mathrm{ppm})$. Furthermore, $\mathbf{2}$ is characterized by two
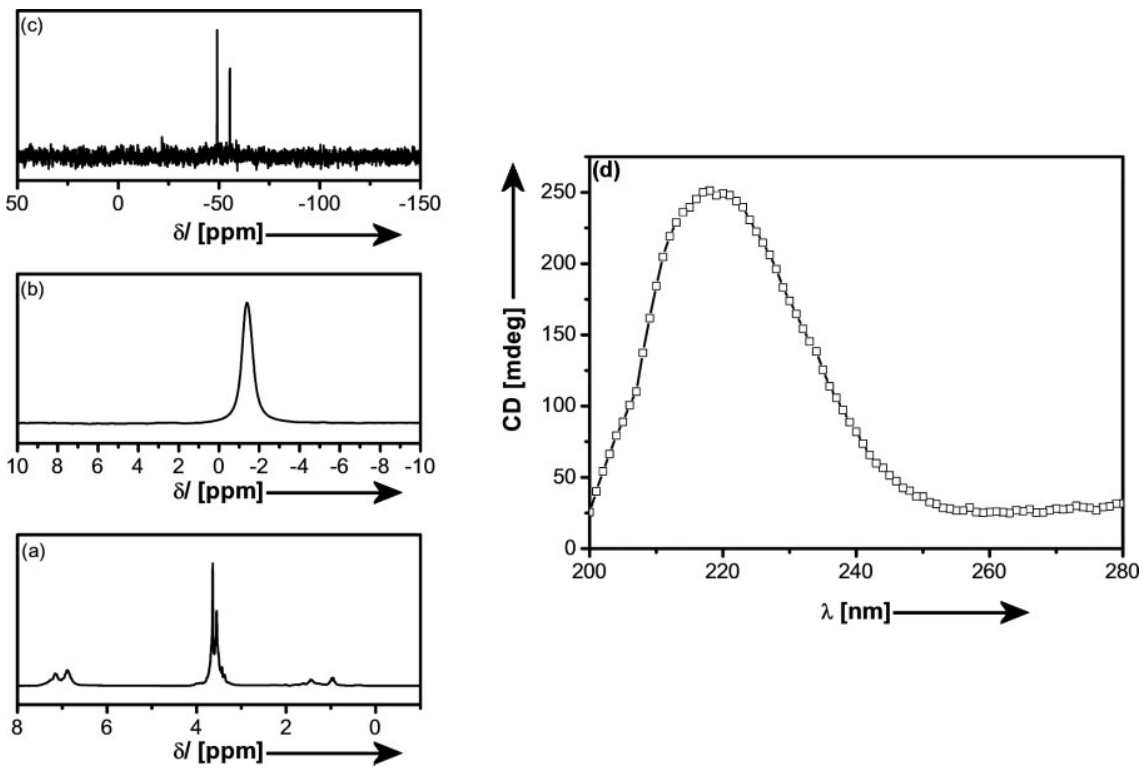

Figure 1. a) ${ }^{7} \mathrm{H} N M R$, b) ${ }^{11} \mathrm{~B} N M R$, and c) ${ }^{29} \mathrm{Si}$ NMR spectra of compound 2. d) Circular dichroism (CD) spectrum of 2 .
${ }^{29} \mathrm{Si}$ NMR signals $(\delta=-48.4,-55.4 \mathrm{ppm})$, which also differ from the starting compound $1(\delta=-58.6 \mathrm{ppm})$. Since we have not been able to obtain single crystals of the substance, in addition to the NMR data the sample has been characterized using electron-impact mass spectrometry (EI-MS) (spectrum not shown). The highest mass peak $(\mathrm{m} / \mathrm{z}=356)$ can be attributed to 2 after the loss of one $\mathrm{CH}_{3} \mathrm{O}^{-}$group; the other signals in the spectrum can also be explained by fragments of $\mathbf{2}$. Therefore, it can be concluded that $\mathbf{2}$ has been successfully synthesized and isolated. Although under the chosen conditions (see Experimental) the reaction takes place only in the presence of the rhodium catalysts, there is still no evidence for the enantioselective aspect of the synthesis. Due to the phenyl ring in $\mathbf{2}$ it is possible to measure the circular dichroism (CD) of the compound. The CD spectrum in Figure 1d shows a clear signal centered at $\lambda=218 \mathrm{~nm}$. Thus, we can conclude that the enantioselective synthesis is successful and we have a chiral PMO precursor.

It is obvious that a standard procedure involving the oxidation of the $\mathrm{B}-\mathrm{C}$ bond with alkaline hydrogen peroxide solutions will also hydrolyze the alkoxysilane groups present in the precursor. Consequently, attempts using hydrogen peroxide have not been successful. Therefore, at first we tried to obtain a PMO material using compound $\mathbf{2}$ directly, using cetyltrimethylammonium bromide (CTAB) as a structure-directing agent. However, instead of a porous material, a reddish gel was obtained, which had no porosity at all. Therefore, prior to the hydrolysis reaction under nonaqueous conditions, we added a stoichiometric amount of an organic peroxide (see Experimental) to a methanolic solution of 2 . After a short reaction time, the mixture is added to a solution of CTAB in aqueous ammonia. After a few minutes a precipitate is formed that could be further character- 
ized by ${ }^{13} \mathrm{C}$ and ${ }^{29} \mathrm{Si}$ solid-state NMR spectroscopy (magic angle spinning NMR (MAS-NMR)), elemental analysis, transmission electron microscopy (TEM), and $\mathrm{N}_{2}$ physisorption.

The ${ }^{13} \mathrm{C}$ MAS NMR spectrum is characterized by three main signals (Fig. 2a). The signals at $\delta=57.3$ and $17.5 \mathrm{ppm}$ can be attributed to the two expected carbon atoms in the organosilicate $\mathrm{O}_{1.5} \mathrm{SiCH}_{2} \mathrm{CHOHSiO}_{1.5}$. The weak low-field signal can be explained by the polycondensation of the unreacted precursor 2 still possessing the catecholboryl group. In an $\mathrm{O}_{1.5} \mathrm{Si}-\mathrm{R}-$ $\mathrm{SiO}_{1.5}$ material, T-silicon centers $\left(\mathrm{R}-\mathrm{SiO}_{3-x}(\mathrm{OH})_{x} ; x=1,2\right)$ are expected to be present. These silicon centers are characterized by the large signal in the ${ }^{29} \mathrm{Si}$ MAS NMR spectrum at $\delta \approx-70 \mathrm{ppm}$, as shown in Figure $2 \mathrm{~b}$. In addition, a minor fraction of Q-type silicon atoms $\left(\mathrm{SiO}_{4-x}(\mathrm{OH})_{x} ; x=1-3\right)$ can be identified from the spectrum at $\delta \approx-110 \mathrm{ppm}$. Deconvolution and integration of the spectra indicates that the ratio of T- to Q-silicon atoms is 4.5:1. This means that as a result of the presence of ROOH not only are the targeted $\mathrm{C}-\mathrm{B}$ bonds cleaved, but to a lesser extent the $\mathrm{C}-\mathrm{Si}$ bonds are also cleaved.

Nevertheless, TEM images (Fig. 3) show that a highly ordered mesoporous material could be obtained. The material is composed of agglomerated particles possessing the typical 2D hexagonal pore-system found for all MCM-41 type materials ( $p 6 m$ symmetry). However, the average pore size $\left(D_{\mathrm{p} ; \mathrm{TEM}}=3 \mathrm{~nm}\right)$ is relatively small.

Further information about the pore system can be obtained from $\mathrm{N}_{2}$-physisorption measurements. The results are shown in Figure 4. An isotherm typical for mesoporous materials is observed with a well-defined capillary condensation step at $p / p^{0} \approx 0.38 .^{[17]}$ The strong adsorption at lower pressures is indicative of the presence of a significant amount of micropores. This means that only a fraction of the total Brunauer-Em-
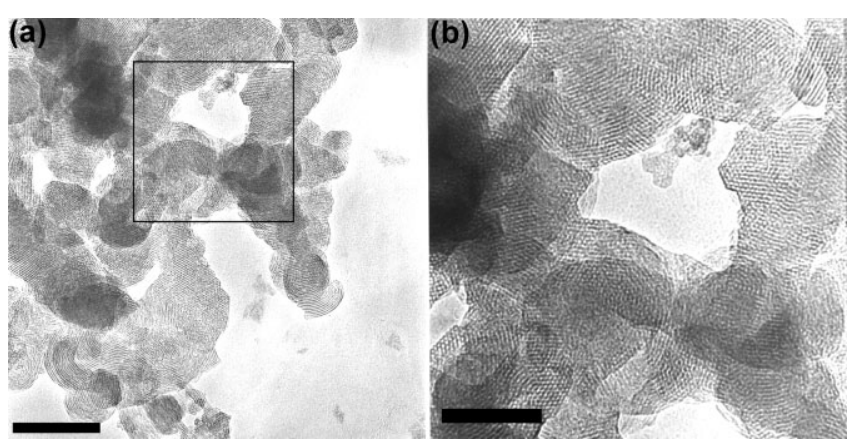

Figure 3. TEM images of the mesoporous $\mathrm{O}_{1.5} \mathrm{SiCH}_{2} \mathrm{CHOHSiO}_{1.5}$ organ osilica materials at two different magnifications: a) scale bar $=150 \mathrm{~nm}$; b) scale bar $=100 \mathrm{~nm}$.

mett-Teller (BET) surface area of $1093 \mathrm{~m}^{2} \mathrm{~g}^{-1}$ can be attributed to the mesopores. The hysteresis observed at higher partial pressures can be explained by the interstitial cavities created by the random condensation of single mesoporous particles, as clearly seen in Figure 3a. The gas condensed in these cavities is released at relatively lower pressures during the desorption process when the smaller access pores are also emp-
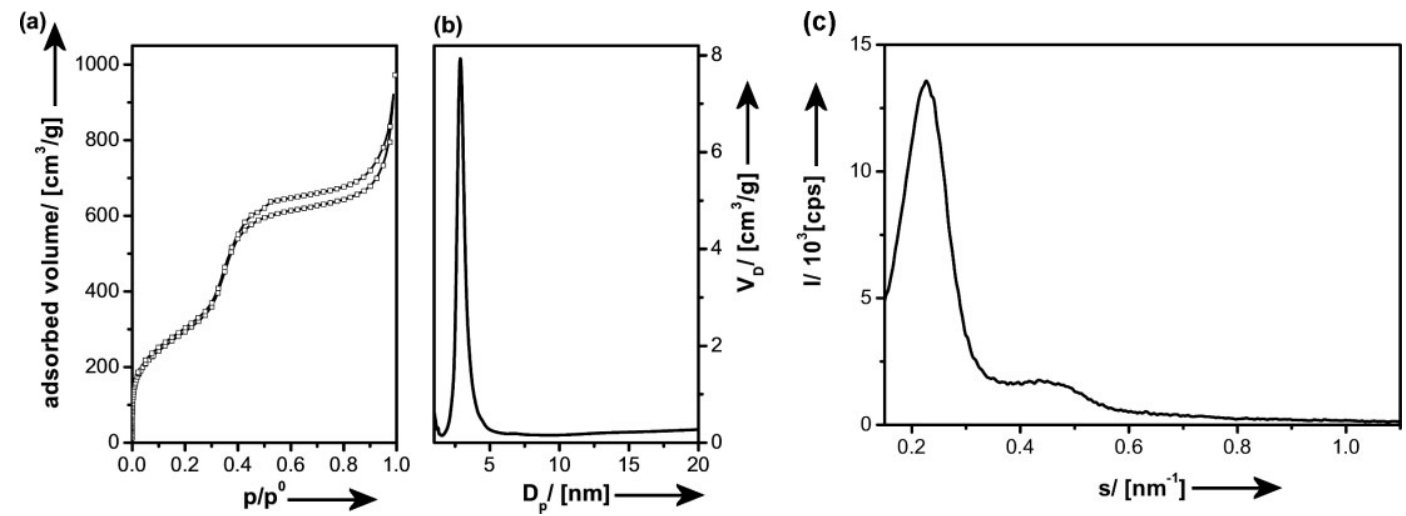

Figure 4. a) Physisorption isotherm and b) pore-size distribution function of the prepared $\mathrm{O}_{1.5} \mathrm{SiCH}_{2} \mathrm{CHOHSiO}_{1.5}$ organosilica material. c) Powder $\mathrm{X}$-ray diffraction data recorded at low angles. $p / p^{0}$ : relative pressure; $D_{\mathrm{p}}$ : pore size, $V_{\mathrm{D}}$ : differential pore volume; s: scattering vector. 
tied. The Barrett-Joyner-Halenda (BJH) pore-size-distribution function calculated from the adsorption branch of the isotherm is shown in Figure $4 \mathrm{~b}$. The data from physisorption are in good agreement with the TEM data. A highly porous material with a defined pore system and an average pore size of $D_{\mathrm{p} ; \mathrm{BJH}}=2.86 \mathrm{~nm}$ has been obtained. The previously discussed results from TEM and $\mathrm{N}_{2}$-physisorption are also in good agreement with powder X-ray diffraction (PXRD) data (Fig. 4c) recorded in the low-angle region. The diffraction pattern shows one main reflection at $s=0.22 \mathrm{~nm}^{-1}$, which corresponds to an interplanar spacing distance $d_{(100)}$ of $4.42 \mathrm{~nm}$.

In summary, we have shown that a well-defined PMO can be produced by using a chiral bis-alkoxysilane sol-gel precursor as the building block. An investigation of the chiral character of the created interfaces is currently in progress, but beyond the scope of this manuscript.

\section{Experimental}

Starting compounds were received from Aldrich, purified, and carefully dried prior to use. The chiral phosphane ligand was received from ABCR GmbH and used as-is. When necessary, chemical reactions were performed under inert-gas conditions using the Schlenk technique. Bis-trimethoxysilylethene was prepared according to the literature [15]. Inside a glove box, $56 \mathrm{mg}$ of $[\mathrm{Rh}(\mathrm{COD}) \mathrm{Cl}]_{2}(\mathrm{COD}=\mathrm{cy}-$ clooctadiene) and $80 \mathrm{mg}$ of enantiomerically pure $R$-BINAP were put together in a $100 \mathrm{~mL}$ Schlenk flask. $50 \mathrm{~mL}$ dry tetrahydrofuran (THF) was added and the solution was stirred for $30 \mathrm{~min}$. Subsequently, $6 \mathrm{~g}(\mathrm{MeO})_{3} \mathrm{SiCH}=\mathrm{CHSi}(\mathrm{OMe})_{3}$ was added and stirred for an additional $30 \mathrm{~min}$. Then, the solution was cooled to $-78^{\circ} \mathrm{C}$ and $22.4 \mathrm{~mL}$ of a catechol borane $(1 \mathrm{~m})$ solution was added dropwise. The reaction mixture was warmed to room temperature and stirred for 5 days. The course of the reaction was monitored in situ by ${ }^{1} \mathrm{H}$ NMR spectroscopy. In contrast to the reaction in the absence of a catalyst, no heating was required for the hydroboration reaction to occur. After vacuum removal of the solvent, a deep red oil was obtained. $60 \mathrm{~mL}$ of dry pentane was added and the catalyst was seen to precipitate out. The solution was cooled to $-20^{\circ} \mathrm{C}$ and filtered over a Schlenk filter. After careful bulb-to-bulb distillation using a turbomolecular pump, $3.04 \mathrm{~g}$ ( $34 \%$ ) of a viscous, colorless liquid 2 was obtained. Separately, $1.4 \mathrm{~g}$ CTAB was dissolved in $25 \mathrm{~mL} \mathrm{H}_{2} \mathrm{O}$ and $13 \mathrm{~g}$ concentrated $\mathrm{NH}_{4} \mathrm{OH}$ solution was added. $2.6 \mathrm{~g}$ of 2 was dissolved in dry methanol containing a stoichiometric amount of tert-butylhydroperoxide. After $1 \mathrm{~h}$ the two solutions were mixed together. A white precipitate was formed rapidly. The dispersion was transferred into a steel autoclave and heated for 2 days at $120^{\circ} \mathrm{C}$. The white solid was collected by filtration and the template was removed by ion-exchange with an aqueous solution of hydrochloric acid in methanol. After filtration and drying, the porous material (3) was obtained.

NMR spectra were acquired on a Bruker Avance DPX $250 \mathrm{spec}-$ trometer using dried $\mathrm{C}_{6} \mathrm{D}_{6}$ as a solvent. Solid-state NMR spectra were recorded using a Bruker DRX 400 spectrometer. The following ex- perimental parameters were used for the measurements. ${ }^{13} \mathrm{C}$ : A crosspolarization pulse program was used with a spin rate of $5 \mathrm{kHz}, 5 \mathrm{~s}$ recycle delay, $2 \mathrm{~ms}$ contact time, and $\pi / 2$ pulse width of $6.2 \mu \mathrm{s} .{ }^{29} \mathrm{Si}$ : A cross-polarization pulse program was used with a spin rate of $5 \mathrm{kHz}$, $40 \mathrm{~s}$ recycle delay, $12 \mathrm{~ms}$ contact time, and a $\pi / 6$ pulse width of $2.2 \mu \mathrm{s}$. CD spectra were acquired on a JASCO J-715 instrument. TEM images were acquired on a Hitachi H-8100 instrument equipped with a $\mathrm{LaB}_{6}$ cathode. $\mathrm{N}_{2}$-physisorption measurements were recorded using a Micromeritics Gemini V instrument. PXRD analyses of all powder samples and deposited particles were performed on a Bruker-AXS D8 Advance instrument using $\mathrm{Cu} \mathrm{K} \alpha$ radiation $(\lambda=1.5418 \AA)$ and a position-sensitive detector.

Received: December 9, 2005 Final version: January 9, 2006

[1] a) J. S. Beck, J. C. Vartuli, W. J. Roth, M. E. Leonowicz, C. T. Kresge, K. D. Schmitt, C. T. Chu, D. H. Olson, E. W. Sheppard, S. B. McCullen, J. B. Higgins, J. L. Schlenker, J. Am. Chem. Soc. 1992, 114, 10 834. b) C. T. Kresge, M. E. Leonowicz, W. J. Roth, J. C. Vartuli, J. S. Beck, Nature 1992, 359, 710.

[2] T. Bein, Curr. Opin. Solid State Mater. Sci. 1999, 4, 85.

[3] Y. Chujo, Curr. Opin. Solid State Mater. Sci. 1996, 1, 806.

[4] a) I. Halasz, I. Sebestian, Angew. Chem. Int. Ed. Engl. 1969, 8, 453. b) S. Polarz, in Handbook of Organic-Inorganic Hybrid Materials and Nanocomposites (Ed: H. S. Nalwa), American Scientific, Stevenson Ranch, CA 2003, p. 165.

[5] a) S. L. Burkett, S. D. Sims, S. Mann, Chem. Commun. 1996, 1367. b) C. E. Fowler, S. L. Burkett, S. Mann, Chem. Commun. 1997, 1769.

[6] a) T. Asefa, M. J. MacLachan, N. Coombs, G. A. Ozin, Nature 1999, 402, 867. b) S. Inagaki, S. Guan, Y. Fukushima, T. Ohsuna, O. Terasaki, J. Am. Chem. Soc. 1999, 121, 9611.

[7] M. J. MacLachlan, T. Asefa, G. A. Ozin, Chem. Eur. J. 2000, 6, 2507.

[8] a) F. C. Peiris, B. D. Hatton, G. A. Ozin, D. D. Perovic, Appl. Phys. Lett. 2005, 87, 241902 . b) W. J. Hunks, G. A. Ozin, J. Mater. Chem. 2005, 15, 3716. c) B. D. Hatton, K. Landskron, W. Whitnall, D. D. Perovic, G. A. Ozin, Adv. Funct. Mater. 2005, 15, 823.

[9] C. Yoshina-Ishii, T. Asefa, N. Coombs, M. J. MacLachlan, G. A. Ozin, Chem. Commun. 1999, 2539.

[10] W. J. Hunks, G. A. Ozin, Adv. Funct. Mater. 2005, 15, 259.

[11] K. Landskron, G. A. Ozin, Science 2004, 306, 1529.

[12] a) K. J. Shea, D. A. Loy, Chem. Mater. 2001, 13, 3306. b) B. D. Hatton, K. Landskron, W. Whitnall, D. D. Perovic, G. A. Ozin, Acc. Chem. Res. 2005, 38, 305.

[13] C. Baleizao, B. Gigante, D. Das, M. Alvaro, H. Garcia, A. Corma, Chem. Commun. 2003, 1860.

[14] a) B. J. Melde, B. T. Holland, C. F. Blanford, A. Stein, Chem. Mater. 1999, 11, 3302. b) S. Inagaki, S. Guan, Y. Fukushima, T. Ohsuna, O. Terasaki, Stud. Surf. Sci. Catal. 2000, 129, 155.

[15] B. Marciniec, J. Gulinski, J. Organomet. Chem. 1984, 266, C19.

[16] a) K. Burgess, M. J. Ohlmeyer, J. Org. Chem. 1988, 53, 5178. b) K. Burgess, M. J. Ohlmeyer, Chem. Rev. 1991, 91, 1179.

[17] S. J. Gregg, K. S. W. Sing, Adsorption, Surface Area and Porosity, Vol. 2, 4th ed., Academic, London 1982. 